\title{
repisälud
}

This is the peer reviewed version of the following article:

Characterization of Novel Missense Variants of SERPINA1 Gene Causing Alpha-1 Antitrypsin Deficiency

Nerea Matamala, Beatriz Lara, Gema Gomez-Mariano, Selene Martínez, Diana Retana, Taiomara Fernandez, Ramona Angeles Silvestre, Irene Belmonte, Francisco Rodriguez-Frias, Marçal Vilar, Raquel Sáez, Igor Iturbe, Silvia Castillo, María MolinaMolina, Anna Texido, Gema Tirado-Conde, Jose Luis Lopez-Campos, Manuel Posada, Ignacio Blanco, Sabina Janciauskiene, Beatriz Martinez-Delgado.

Am J Respir Cell Mol Biol. 2018 Jun;58(6):706-716.

which has been published in final form at https://doi.org/10.1165/rcmb.2017-01790C 


\section{Characterization of novel missense variants of SERPINA1 gene causing alpha-1 antitrypsin deficiency}

Nerea Matamala ${ }^{1}$, Beatriz Lara ${ }^{2}$, Gema Gomez-Mariano ${ }^{1}$, Selene Martínez ${ }^{1}$, Diana Retana ${ }^{1}$, Taiomara Fernandez ${ }^{1}$, Ramona Angeles Silvestre ${ }^{3}$, Irene Belmonte ${ }^{4}$, Francisco Rodriguez-Frias ${ }^{4}$, Marçal Vilar ${ }^{5}$, Raquel Sáez ${ }^{6}$, Igor Iturbe ${ }^{7}$, Silvia Castillo ${ }^{8}$, María Molina-Molina ${ }^{9}$, Anna Texido ${ }^{10}$, Gema Tirado-Conde ${ }^{11}$, Jose Luis Lopez-Campos ${ }^{12}$, Manuel Posada ${ }^{13}$, Ignacio Blanco ${ }^{14}$, Sabina Janciauskiene $^{15}$, Beatriz Martinez-Delgado ${ }^{1}$.

${ }^{1}$ Molecular Genetics Unit, Instituto de Investigación de Enfermedades Raras (IIER). Instituto de Salud Carlos III (ISCIII), Madrid. Spain.

${ }^{2}$ Respiratory Medicine Dept., Coventry University Hospital, Coventry, UK.

${ }^{3}$ Biochemistry Unit. Hospital Puerta de Hierro, Madrid, Spain.

${ }^{4}$ Biochemistry Dept. Hospital Vall d'Hebron. Barcelona. Spain

${ }^{5}$ Instituto de Biomedicina de Valencia-CSIC. Valencia. Spain

${ }^{6}$ Inmunology and Genetics, Hospital Donosti, San Sebastián, Spain

${ }^{7}$ Neumology. Hospital de Zumárraga, Gipuzkoa, Spain.

${ }^{8}$ Pediatrics, Hospital Clínico de Valencia, Valencia, Spain

${ }^{9}$ Pulmonary Medicine, Bellvitge University Hospital-IDIBELL, Hospital de Llobregat, Barcelona, Spain.

${ }^{10}$ Pneumology, Hospital Universitary Sant Joan de Reus, Reus (Tarragona), Spain.

${ }^{11}$ Complejo Hospitalario Universitario Granada. Parque Tecnológico de las Ciencias de la Salud. Granada. Spain.

${ }^{12}$ Unidad Médico-Quirúrgica de Enfermedades Respiratorias. Instituto de Biomedicina de Sevilla (IBiS). Hospital Universitario Virgen del Rocio/ Universidad de Sevilla, Spain; and CIBER de Enfermedades Respiratorias (CIBERES). Instituto de Salud Carlos III, Madrid,Spain.

${ }^{13}$ Instituto de Investigación de Enfermedades Raras (IIER) \& CIBERER. Instituto de Salud Carlos III (ISCIII), Madrid. Spain.

${ }^{14}$ Alpha1- Antitrypsin Deficiency Spanish Registry (REDAAT), Spanish Society of Pneumology (SEPAR). Fundación Española de Pulmón (RESPIRA), Barcelona. Spain.

${ }^{15}$ Department of Respiratory Medicine, Hannover Medical School, Biomedical Research in Endstage and Obstructive Lung Disease Hannover (BREATH), Member of the German Center for Lung Research (DZL), Hannover, Germany.

Author's Contributions: NM: performed experiments, analyzed data, and drafted manuscript. BL: collected clinical data, interpretation results and draft the manuscript. GGM, SM, DR, TF: performed experiments and analyzed data. RAS: Obtained and analyzed biochemical results, review manuscript. IB, FRF: performed IEF analysis, interpretation of the results. MV: performed protein structure analysis and interpretation of the results. RS, II, SC, MMM, AT, GTC, JLC: reviewed patient's clinical data, interpreted results, helped in drafting manuscript. MP, IgB: participated in collection of samples, interpretation of the results, drafting the manuscript and revising it critically. SJ: participated in protein expression analysis, interpretation of results, drafting the manuscript. BMD: design and coordination of the study and draft the manuscript. All authors read and approved the final manuscript.

Corresponding author: Beatriz Martinez-Delgado. Molecular Genetics. Instituto de Investigación en Enfermedades Raras (IIER). INSTITUTO DE SALUD CARLOS III. Ctra. Majadahonda-Pozuelo Km2,200. 28220 Madrid.Spain. Tel:+34918223152, Fax:+3918223269. Email: bmartinezd@isciii.es

Running title: Characterization of novel missense AAT variants. 


\begin{abstract}
SERPINA1 gene is highly polymorphic, with more than one hundred variants described in databases. The SERPINA1 encodes alpha-1 antitrypsin (AAT) protein, and the severe deficiency of AAT is a major contributor to pulmonary emphysema and liver diseases. In Spanish patients with AAT deficiency we identified seven new variants of SERPINA1 gene involving amino acid substitutions in different exons: PiSDonosti (S+Ser14Phe), PiTijarafe (Ile50Asn), PiSevilla (Ala58Asp), PiCadiz (Glu151Lys), PiTarragona (Phe227Cys), PiPuerto Real (Thr249Ala) and PiValencia (Lys328Glu). We examined the characteristics of these variants and the putative association with the disease. Mutant proteins were overexpressed in HEK293T cells and AAT expression, polymerization, degradation and secretion as well as anti-elastase activity were analyzed by PAS staining, western blot, pulse-chase and elastase inhibition assays. When overexpressed, S+S14F, I50N, A58D, F227C and T249A variants formed intracellular polymers and did not secrete AAT protein. Both, E151K and $\mathrm{K} 328 \mathrm{E}$ variants secreted AAT protein and did not form polymers although K328E showed intracellular retention and reduced anti-elastase activity. We conclude that deficient variants may be more frequent than previously thought, and their discovery can only be possible by the complete sequencing of the gene and subsequent functional characterization. Better knowledge of SERPINA1 variants would improve diagnosis and management of AAT deficiency carriers.
\end{abstract}

\title{
KEYWORDS
}

alpha-1 antitrypsin deficiency, SERPINA1 novel variants, AAT polymers, elastase 


\section{INTRODUCTION}

Alpha-1-antitrypsin (AAT) deficiency (AATD) is a genetic condition characterized by low serum levels of AAT (normal serum levels of AAT are 1.3-2 g/L). The AATD is caused by mutations in the SERPINA1 gene and is linked to increased risk for liver diseases, early-onset pulmonary emphysema and, more rarely systemic vasculitis, necrotizing panniculitis and probably other diseases $[1,2]$.

The laboratory testing for AATD typically involves analysis of AAT protein concentration by nephelometry and the identification of specific alleles by phenotyping and genotyping using defined diagnostic algorithms $[3,4]$. Despite the American Thoracic Society/European Respiratory Society recommendations for the testing, diagnosis and management of AATD [5], this condition remains underdiagnosed.

To identify AAT variants, based on the AAT protein migration patterns, isoelectric focusing (IEF) is typically used [6]. This method allows the characterization of about 30 normal and pathological variants (e.g. M, I, F, S, and Z). However, a number of rare variants, such as PiMmalton, PiMpalermo, or PiMheerlen, have an isoelectric point similar to the normal $\mathrm{M}$ alleles. Therefore, one cannot be certain that phenotyping will identify all variants. Another drawback is that IEF technique cannot detect null alleles. Besides, the recognition of unusual variants of AAT by IEF requires an adequate expertise. Genotyping using allele-specific polymerase chain reaction (PCR) methodologies can detect S, Z, F or MMalton alleles and analytical genotyping kits are available that can measure $\sim 25$ AATD alleles [7,8]. Nevertheless, these methods may also disregard some of the rare and null alleles. Therefore, the sequence analysis of the AAT gene is the reference method for identifying and characterizing rare and null variants of AAT. This method relays on the complete analysis of the DNA sequence of the four coding exons of the SERPINA1 gene and, for particularly rare cases involves analyses of the intronic and regulatory sequences [9].

The AAT is about $52 \mathrm{kDa}$ glycoprotein predominantly produced in the liver and secreted to extracellular milieu where it exerts protease inhibitory and anti-inflammatory functions. The commonest deficient variants of AAT are the S (Glu264Val) and Z (Glu342Lys). The combination of these alleles into the ZZ and SZ genotypes accounts for the vast majority of severe AATD-related diseases. Other rare alleles of AAT are also associated with reduced serum level of AAT protein [10]. The molecular mechanism underlying the deficiency is either the increased intracellular proteolysis or aggregation of AAT protein [11]. The PiMmalton (Phe52del) and PiSiiyama (Ser53Phe) are two well-known deficiency variants of AAT $[12,13]$. All these variants form intracellular polymers and give a positive response to periodic acid-Schiff (PAS) staining [13].[11]

To date, over 100 rare genetic variants of human AAT are known although most of them are not well characterized $[11,14]$. These variants occur mainly due to the amino acid substitutions or deletions, 
which result in deficiency [11], or absence (null variants) of AAT [10]. The discovery of rare variants is continuously increasing, specifically in subjects with lower levels of AAT $[9,15,16]$, and many of them remain of unknown significance.

In the present study, we report seven new variants of SERPINA1 gene found in subjects with deficient levels of AAT. When overexpressed, some of these variants form intracellular polymers or accumulate within the cell, show low secretion or reduced anti-elastase activity. These new variants help to increase our knowledge on the structural and functional properties of AAT protein and awareness of the existence of variants with unknown significance. 


\section{MATERIAL AND METHODS}

\section{Cases}

Patient samples and their clinical data were obtained from the REDAAT, Spanish Registry of Alpha1 Antitrypsin Deficiency patients. A total 972 cases, enrolled between 2013-2016 years, were routinely genotyped for $\mathrm{S}$ and $\mathrm{Z}$ variants at the Molecular Genetics Unit of the IIER/ISCIII. Based on Spanish guidelines [17] providing the reference serum concentration for specific genotypes, extended genotype analysis was undertaken for the cases with: i) discrepancies between serum AAT level and allele-specific genotype; ii) AAT level in the lower limit of the range for the corresponding genotype; and iii) AAT level not discordant but case has severe clinical manifestations.

Out of 192 sequenced cases, 101 (52.6\%) carried at least one of already known variants of AAT (MMalton, Mattawa, MProcida...), whereas eight cases (3.6\%) had previously not described AAT variants. Clinical data of these eight patients are shown in Table 1. All of them had lung disease except for one male with a chronic diarrhea of unspecified etiology and one asymptomatic female (low serum level was detected based on the family screening). The routine blood tests for liver function revealed no evidence of liver disease in these cases. Signed informed consent for the study was obtained from all the subjects and the research was approved by the ethics committee of Instituto de Salud Carlos III, Madrid, Spain.

\section{Sequencing of SERPINA1 gene}

DNA was extracted from peripheral blood using standard methods. The coding sequence of the gene (exons 2 to 5) and exon-intron junctions were analyzed by means of a Sanger automated sequencing (ABI PRISM 377 Applied BioSystems), using previously described primers [18,19]. Sequences were compared to reference SERPINA1 sequences (NG_008290.1, NM_000295.4) and new variants were identified.

\section{Allele frequency and functional prediction of genetic variants}

We sought for the presence and frequency of the new identified SERPINA1 variants in dbSNP (https://www.ncbi.nlm.nih.gov/SNP/), the Exome Aggregation Consortium (ExAC) (http://exac.broadinstitute.org) and the CIBERER Spanish Variant Server (CSVS) (http://csvs.babelomics.org/). Two algorithms, SIFT (http://sift.jcvi.org/) and PolyPhen (http://genetics.bwh.harvard.edu/pph2/), were used to predict whether an amino acid change affects protein structure and function. 


\section{Isoelectric focusing of AAT}

When serum was available, the phenotype of the new variants was determined by isoelectric focusing (IEF) analysis, as previously described [20]. Comparison with sera of known phenotype allowed determining whether the new variant modifies AAT migration.

\section{Cloning of the new alleles}

The genetic background of the PiSDonosti, PiSevilla and PiTarragona alleles was determined by cloning experiments. The PCR products of exon 2 (PiSDonosti and PiSevilla) and exon 3 (PiTarragona) from the index case's DNA were cloned into pGEM-T Easy vector (Promega, Madison, WI, USA), introduced into E. coli DH5 $\alpha$ and sequenced.

\section{Expression plasmids and DNA transfection}

The expression vector pCMV6 (OriGene, Rockville, MD, USA) with AAT M1(Val213) cDNA was used for expression of the new identified SERPINA1 variants. PiZ, PiS and the seven new variants were introduced into the wild type AAT cDNA by site-directed mutagenesis using the QuikChange II Site-Directed Mutagenesis Kit (Stratagene, La. Jolla, CA, USA), according to the manufacturer's instructions, and the primers described in Supplementary Table E1. In the case of PiSDonosti variant, two expression vectors were generated: one only containing the Donosti substitution (Ser14Phe) and other containing both S (Glu264Val) and Donosti (Ser14Phe) changes. The HEK293T cells were transiently transfected in 6-well plates with 10 ul of DNA Transfection Reagent (Biotool) and 4 ug of expression plasmid in serum-free Opti-MEM culture medium (Gibco, Carlsbad, CA, USA). Cell pellets and conditioned media were harvested 48 hours after transfection, and used for following experiments.

\section{Protein electrophoresis and western blot analysis}

Cell pellets were lysed by using RIPA buffer with Complete Protease Inhibitor Cocktail (Roche, Mannheim, Germany). After RIPA digestion, cell lysates and insoluble elements containing cell membranes were collected. The insoluble pellets were sonicated to obtain retained proteins. Cell media were also collected after $48 \mathrm{~h}$ of transfection. 10\% acrylamide sodium dodecyl sulfate polyacrylamide gel electrophoresis (SDS-PAGE) was performed on cell lysates and media, while insoluble fractions were subjected to $8 \%$ acrylamide non-denaturing PAGE. The proteins were transferred from the gels onto PVDF membranes and blots were probed with either 1:2,000 antiAAT B9 (sc-59438 Santa Cruz Biotechnology, Santa Cruz, CA, USA) or 1:1,000 anti-AAT 2C1 (HyCult Biotech, Uden, The Netherlands), followed by 1:5,000 goat anti-mouse IgG-HRP (Santa Cruz Biotechnology, Santa Cruz, CA, USA). Mouse anti- $\beta$-actin (AC-74 Sigma Aldrich, Munich, Germany) was used as a loading control. 


\section{Detection of aggregates with PAS staining}

The periodic acid-Schiff (PAS) stain is used to assist in the diagnosis of AAT deficiency, where accumulation of AAT aggregates is seen as bright magenta globules. To detect intracellular accumulation of the new identified mutants, transfected cells were washed in cold PBS and cytospins were prepared. After fixation in 95\% ethanol, samples were stained with Hematoxylin-Eosin and Periodic-Acid-Schiff (PAS). PAS staining was performed on both HEK293T and HepG2 cell lines.

\section{Elastase Inhibition assay}

Elastase inhibition assays were performed with the new AAT variants secreted to the conditioned media of transfected cells. The concentration of AAT was measured by immune nephelometry and equal amounts of protein were used for the assays. Briefly, conditioned media was incubated with porcine pancreas elastase (Sigma Aldrich, Munich, Germany) at $37^{\circ} \mathrm{C}$ for 5 ' and SucAla3-pNA (Sigma Aldrich, Munich, Germany) was added as elastase substrate. The increase in absorption at $405 \mathrm{~nm}$ was measured for 60'. Conditioned media from cells transfected with an empty vector was used as a negative control (no elastase inhibition, maximum increase in absorption), and media from cells transfected with wild type SERPINA1 was used as a positive control (elastase inhibition, low increase in absorption).

\section{Pulse-chase experiments}

Transfected cells were pulsed for $1 \mathrm{~h}$ with cysteine and methionine-free DMEM (Gibco, Waltham, MA USA) supplemented with $35^{\mathrm{S}}$ Met/Cys (Hartmann Analytic, Germany), and chased at 0, 0,5, 1, 2, 4 and 5 hours with complete DMEM (Lonza, Basel, Switzerland) without labeling reagent. Cells were lysed in RIPA Buffer (Sigma Aldrich, Munich, Germany) and sonicated. After centrifugation at $14,000 \mathrm{rpm}$, intracellular fractions were subjected to immunoprecipitation with anti-AAT antibody B9 (sc-59438 Santa Cruz Biotechnology, Santa Cruz, CA, USA) and analyzed by SDSPAGE/autoradiography.

\section{Localization of variants in the protein structure}

The position of the new AAT variants was indicated on the crystal structure of $\alpha 1$-antitrypsin PDB code: 3NE4 [21] using the Visual Molecular Dynamics, VMD 1.9.2 software [22]. Different representations available in the VMD software were used like ribbons and surf. Mutated residues were highlighted as colored spheres using the VDW (van der Waals) representation. 


\section{RESULTS}

\section{Identification of new AAT genetic variants}

After the initial genotyping ( $\mathrm{S} / \mathrm{Z}$ alleles), we sequenced coding exons of SERPINA1 gene in eight discordant cases. Our results revealed seven previously unknown variants, which define new alleles contributing to the deficiency of AAT. Variants were named according to the birthplace of the carrier or where the diagnosis took place [23] (Table 2).

\section{PiSDonosti (PiS +Ser14Phe)}

Two unrelated patients carried the S14F variant in heterozygosity. Case 1 was a 59-year-old female former smoker (30 pack-year) suffering from mild COPD. Her lung function tests showed FEV1 $72 \%$ of predicted (volume of air forcefully exhaled in 1 second percent of predicted) FVC $85 \%$ of predicted (forced vital capacity percent of predicted), and Tiffeneau-Pinelli index (FEV1/FVC 60). Her initial diagnosis was PiSS, with AAT serum levels of $76 \mathrm{mg} / \mathrm{dL}$. Case 2 was a 40 -year-old male never smoker diagnosed with idiopathic pulmonary fibrosis. The patient was diagnosed as PiSZ with AAT serum levels of $67 \mathrm{mg} / \mathrm{dL}$. For both cases, DNA sequencing revealed a C $>$ T transition in exon 2 (NM_000295.4, c.113C > T). This change produces a substitution of serine for phenylalanine at codon 14 (Ser14Phe). Cloning experiments demonstrated that this new variant segregates with the $\mathrm{S}$ allele. This change is described in dbSNP as rs745463238, and it was also found in ExAC Browser, but with a low frequency $<1 / 10,000$. The substitution was predicted as tolerated by SIFT and possibly damaging by PolyPhen. This Ser14 (in the full protein Ser38) has been described to be phosphorylated [24].

\section{PiTijarafe (Ile50Asn)}

The index case was a 39-year-old male never smoker who suffered from chronic diarrhea of undetermined cause. His serum levels of AAT were low $(75 \mathrm{mg} / \mathrm{dL})$ and not concordant with the initial diagnosis of PiMM. Gene sequencing revealed a novel change of ATC to AAC at codon 50 in exon 2 (NM_000295.4, c.221T $>$ A) producing an amino acid change of isoleucine to asparagine (Ile50Asn). This variant is not described in any of the genetic databases consulted and was predicted as deleterious by SIFT, and probably damaging by PolyPhen. This Ile50 is located very close to the Phe52 deleted in the PiMmalton allele.

\section{PiSevilla (Ala58Asp)}

This case was a 64-year-old male, a former smoker (22 pack-year) with a history of severe COPD (FEV1\% 33, FVC\% 73, FEV1/FVC 35), initially diagnosed as PiMZ with serum AAT levels of 35 $\mathrm{mg} / \mathrm{dL}$. Gene sequencing showed a C $>\mathrm{A}$ transversion in exon 2 (NM_000295.4, c.245C $>\mathrm{A}$ ), changing GCT for GAT at codon 58 (Ala58Asp). The substitution appeared in a M1(Val) 
background. This variant has not been reported in any database and was predicted as tolerated by SIFT, and possibly damaging by PolyPhen.

$\underline{\text { PiCadiz (Glu151Lys) }}$

The case was a 67-year-old male, never smoker diagnosed with severe asthma (FEV1\% 52, FVC\% $55 \mathrm{FEV} 1 / \mathrm{FVC} 64)$. The serum level of AAT was low $(81 \mathrm{mg} / \mathrm{dL})$ being initially diagnosed as PiMM genotype. DNA sequencing revealed a $\mathrm{G}>\mathrm{A}$ transition at a codon 151 changing GAA to AAA in exon 2 (NM_000295.4, c.523G>A). This change is described in dbSNP database as rs149770048, but shows a very low minor allele frequency of $<1 / 10,000$ (ExAC). SIFT and PolyPhen predict this variant as tolerated and benign, respectively.

\section{PiTarragona (Phe227Cys)}

The case was a 64-year-old male current smoker (80 pack-year) suffering from very severe COPD (FEV1\% <20), initially diagnosed with PiMS genotype having serum AAT levels of $85 \mathrm{mg} / \mathrm{dL}$. Sequence analysis showed a $\mathrm{T}>\mathrm{G}$ transversion in exon 3 (NM_000295.4, c.752T $>\mathrm{G}$ ) producing an amino acid change of phenylalanine to cysteine (Phe227Cys). This variant has been described in dbSNP as rs759837735 and is also present in ExAC Browser with a very low frequency (only one reported allele). Cloning experiments revealed that $\mathrm{F} 227 \mathrm{C}$ was not in the $\mathrm{S}$ allele but arose on an $\mathrm{M} 2$ (rs709932) background. SIFT and Polyphen predict this variant as deleterious and possibly damaging. This variant creates a new Cys residue in the protein. The only Cys in the native AAT is located five residues after the newly created Cys. This suggests putative occurrence of disulfide bond between Cys232 and the new Cys227, which likely affects the structure of this mutant protein.

PiPuerto Real (Thr249Ala)

The case was a 68 -year-old male former smoker (50 pack-year) diagnosed with mild COPD (FEV1\% 88, FVC\% 106, FEV1/FVC 59), and AAT serum levels of $75 \mathrm{mg} / \mathrm{dL}$ and initial diagnosis with PiMM genotype. Sequencing analysis showed an $A>G$ transition at codon 249 of exon 3 (NM_000295.4, c.817A $>$ G) which changes threonine to alanine (Thr249Ala). This Thr249 is part of the glycosylation signal for one of the glycosylation chains of the AAT protein at Asn247. The Nlinked glycosylation typically occurs at the N-X-T/S motif, where $\mathrm{X}$ is any amino acid, except the Proline. Thus, we assume that this variant cannot be glycosylated at Asn247. This variant has not been previously reported in databases and is predicted as deleterious by SIFT and benign by PolyPhen.

\section{PiValencia (Lys328Glu)}

This variant was found in a heterozygous PiMS mother of a child with PiSS genotype. The case was 38-year-old woman never smoker, asymptomatic with normal lung function with reduced serum levels of AAT $(87 \mathrm{mg} / \mathrm{dL})$. This variant consists on an A>G transition in exon 4 (NM_000295.4, 
c. $1054 \mathrm{~A}>\mathrm{G}$ ) producing a lysine to glutamate change (Lys328Glu). The variant appeared in a M1(Val) background and is previously unknown in dbSNP, ExAC or the CSVS databases. It is predicted as deleterious by SIFT and probably damaging by PolyPhen.

\section{Phenotyping of three new variants by isoelectric focusing (IEF)}

Regrettably, plasma samples for IEF were available only from case 2 (PiS+S14F), case 5 (E151K), and case 6 (F227C). As shown in Figure 1, case 6 with the F227C displays IEF pattern similar to that of PiMS, which could explain the initial diagnosis of this case. However, case 6 shows a double band at position five, which is not found in the MS phenotype. Moreover, it does not show the PiMS phenotype's characteristic last band at position 7. For case 5, IEF showed similar pattern as PiMZ, probably because of the same amino acid substitution as in PiZ allele. However, E151K migrated faster than the PiZ variant (Figure 1). The case 2 showed a clear PiSZ protein phenotype, indicating that addition of the S14F mutation does not modify the mobility of AAT bands (Figure 1).

\section{Expression and release of mutated AAT proteins in cell models}

After $48 \mathrm{~h}$ of transfection, the expression of the new variants was compared to the expression of the wild type (wt) and the $\mathrm{S}$ and $\mathrm{Z}$ variants. In two cases, the S14F was in the PiS allele. Therefore, we analyzed this variant alone as well as in a combination with PiS. For most of the variants we found a lower expression of the monomeric AAT protein (Figure 2). The double mutant PiS $+\mathrm{S} 14 \mathrm{~F}$ as well as I50N, A58D and F227C mutants resembled S and Z mutants, in which the AAT protein was almost undetectable. However, the S14F alone, E151K, K328E and T249A mutants were easily detected, similarly to the wt AAT although the T249A mutant showed a lower molecular size of AAT protein. This latter supports the notion that T249A affects the glycosylation of the AAT protein by eliminating the $\mathrm{N}$-glycosylation chain at Asn247.

The analysis of AAT protein in the cell supernatants revealed that S14F, E151K, T249A and K328E mutants are secreted (Figure 2). The monomeric AAT protein was not detected in the supernatants obtained from PiS+S14F, I50N, A58D and F227C mutants suggesting the retention of AAT protein inside the cells.

\section{Polymers and aggregates of AAT variants}

Periodic acid-Schiff (PAS) staining was used to detect intracellular AAT in cells expressing new variants of AAT. As expected, PiS and PiZ mutants showed a positive PAS staining in transfected cells, which is characteristic of the intracellular accumulation of AAT polymers (Figure 3). Five of the variants, PiS +S14F, I50N, A58D, F227C and T249A also showed PAS+ intracellular aggregates. 
These variants, except for T249A, did not secrete AAT into cell supernatants (Figure 2). Interestingly, even being PAS + , the T249A secreted detectable levels of AAT protein. Similar to the wt AAT, S14F alone, E151K and K328E variants did not show PAS+ staining. This is in agreement with the detection of monomeric AAT in cell extracts and supernatants expressing these variants. Therefore, the pathogenic effect of the S14F, E151K and K328E variants is not mediated by the intracellular aggregation of the protein, although the alteration of other functional aspects of AAT cannot be discarded. Similar results were obtained by using HepG2 cells endogenously expressing AAT (Supplementary Figure S1).

Next, anti-total human AAT antibodies were used to detect AAT in cellular fractions (Figure 4A). As expected, the insoluble fraction of cells expressing PiS and PiZ AAT contained polymers of AAT. Insoluble fractions collected from five novel variants, PiS+S14F, I50N, A58D, F227C and T249A also showed polymers of AAT. Except for T249A, AAT polymers correlated well with reduced monomeric AAT in cell extracts and supernatants. The T249A variant seems to polymerize intracellularly but also was secreted as a monomer. We found no polymers in cells expressing wt AAT, S14F, E151K and K328E variants (Figure 4A). Because PiS+S14F, but not S14F, formed polymers, we were not able to find out if S14F contributes to the polymerization of PiS.

Similarly, after sonication of insoluble fractions, we detected similar AAT polymers with $2 \mathrm{C} 1$ antibody, or with a rabbit anti-total AAT antibody (figure 4B). The detection of AAT polymers by using $2 \mathrm{C} 1$ antibody gave similar results to those obtained with anti-total AAT antibody. However, PAS+ aggregates and polymers detected in the sonicated fractions using anti-total AAT antibody correlated better than PAS+ aggregates and the 2C1-detected polymers. Altogether, our results show that the variants PiS+S14F, I50N, A58D, F227C and T249A form intracellular aggregates hampering secretion of AAT protein.

\section{Elastase inhibitory activity of AAT variants}

Since the S14F, E151K, K328E and T249A variants secreted AAT; we wondered whether these mutants preserve some anti-elastase activity. Supernatants from cells transfected with either an empty vector or wt AAT were included as controls (Figure 5). As expected, the maximum elastase activity corresponded to supernatants from the cells transfected with the empty vector. In contrast, supernatants from the cells expressing wt AAT inhibited elastase by $90 \%$ relative to those expressing the empty vector (Figures 5A and B). The S14F, E151K and T249A variants inhibited elastase activity by $97 \%, 94 \%$ and $98 \%$, respectively. However, the anti-elastase activity of K328E mutant was only $68 \%$ relative to the empty vector expressing cells. This latter finding shows that the K328E mutant, although secreted, has lower inhibitory activity than other secreted variants of AAT. 


\section{Degradation and stability of novel variants}

We investigated the degradation dynamics of the novel variants by pulse-chase experiments. Wild type AAT was rapidly lost over the five hours of chase experiment while Z AAT disappeared slowly, indicating its intracellular retention (Figure 6). The novel E151K, S+S14F and F227C variants of AAT disappeared in pulse-chase experiments similarly as wtAAT. Since E151K was secreted into the medium and did not form intracellular polymers, we expected this behavior. On the contrary, $\mathrm{S}+\mathrm{S} 14 \mathrm{~F}$ and F227C polymerized and were not secreted, thus a rapid degradation of polymers might be an explanation for their fast disappearance. The rest of the variants, I50N, A58D, T249A and K328E showed stabilization of the protein comparable to Z AAT. Consistently, I50N, A58D and T249A formed intracellular polymers whereas K328E was found to be secreted and did not polymerize (Figures 2 and 3). Why K328E mutant retains intracellularly remains to be investigated.

\section{Localization of AAT variants on protein tertiary structure}

To get some insights into the effects of new mutations on the properties of AAT protein, we checked their locations on protein structure. Figure 7A shows where the amino acid substitution occurs for each variant (depicted in green) as well as for the PiS and PiZ (in red). Unfortunately, the position of the S14F variant is not shown, because it locates at the beginning of the protein, outside of the folded structure. The I50N and A58D localized in the $\beta$-strand s1A and the $\alpha$-helix $\mathrm{hB}$ respectively within the PiMmalton region. The F227C localized at the end of the $\beta$-strand s1D, very close to the position of the PiZ in the tertiary structure. The T249A was at the start of the s4A strand and, as mentioned above, it disturbs the glycosylation signal for the N247. The E151K localized at the beginning of the $\alpha$-helix hF, and the K328E occurs at the end of the $\beta$ hairpin before the $\beta$-strand s5B. The latter two variants localized in the lower part of the protein, in the opposite side of the reactive loop. Interestingly, variants that formed polymers had amino acid mutations within the interior core of the protein (Figure 7B). Two variants, E151K and K328E that did not form polymers, involved amino acids exposed at the surface of the protein. 


\section{DISCUSSION}

Seven new SERPINA1 alleles (PiSDonosti, PiTijarafe, PiSevilla, PiCadiz, PiTarragona, PiPuerto Real and PiValencia) were identified in Spanish patients. Five of these alleles, namely PiSDonosti (S+S14F), PiTijarafe (I50N), PiSevilla (A58D), PiTarragona (F227C) and PiPuerto Real (T249A), were associated with intracellular polymerization of AAT protein when tested in cellular models overexpressing mutated alleles. Two other alleles, PiCadiz (E151K) and PiValencia (K328E), were expressed and secreted, although PiValencia had lower anti-elastase activity and seemed to be slowly degraded inside the cell. Hence, these new alleles expand the current list of SERPINA1 gene variants known to cause AATD.

The polymerization of AAT protein is a well-known mechanism in the pathogenesis of AAT deficiency [25]. A number of AAT variants, such as Z (Glu342Lys), S (Glu264Val), I (Arg39Cys), Siiyama (Ser53Phe) and Mmalton (Phe52del) form intracellular polymers causing impaired protein secretion of AAT into the bloodstream [12,26-28]. Similar to these variants, the newly identified I50N, A58D, F227C and T249A variants form PAS+ intracellular aggregates containing AAT polymers. In parallel, the lower release of AAT into the medium suggests that these new variants are pathogenic. Specifically, I50N and A58D mutations, localized in the Mmalton region, seem to behave similarly with regard to the polymer formation and reduced secretion.

Of note, T249A was found in a form of intracellular polymers as well as secreted monomers, although at a lower concentration than the wild type AAT. Interestingly this variant seems to avoid the glycosylation at Asn247 because of the destroyed N-X-T glycosylation signal. Since this variant passes through the ER and Golgi, we speculate that a loss of glycosylation does not affect protein secretion but may affect half-life and/or immune modulatory properties of AAT, as it has been previously suggested [29-32]. This idea warrants further investigations.

Another interesting amino acid substitution causing polymerization is $\mathrm{F} 227 \mathrm{C}$, which produces a new Cys residue close to Cys232, the only cysteine residue present in the wild-type M AAT sequence. The cysteines normally form disulphide bonds in the ER [33]. Actually, in the cells expressing the Z or other polymerizing AAT variants, covalent inter-Cys232 homodimers occur. The prevention of such disulphide linkages seems to increase Z AAT secretion [34]. Therefore, we predict that in a F227C mutant, the Cys227 might form an internal disulfide bond with Cys232, resulting in AAT polymerization. This mutant shows an altered mobility in IEF, which supports conformational changes of AAT protein. Nevertheless, the resulting polymers seem to be rapidly degraded, as it has already been described for PiS [35].

The variant S14F was found in two cases, with SS and SZ phenotypes, revealing a new PiS-like allele (PiSDonosti) that might have different characteristics than the classical PiS allele. Nevertheless, S14F by its own did not accumulate in cells in form of polymers, as it happened with 
PiS and with the double mutant PiS+S14F (PiSDonosti). In addition, intracellular PiS+S14F was rapidly degraded, as it has been described for PiS [35]. Therefore, an increased polymerization and/or polymer stabilization does not seem to be the cause of S14F pathogenicity. The Ser14 that is lost in this mutation has been reported to be phosphorylated [24]. Since Ser359 in the reactive center of AAT is another serine residue found to be phosphorylated [36], we speculate that Ser14 might have a functional relevance. Phosphorylation is an important mechanism for activation and deactivation of proteins. However, the importance of phosphorylation in AAT protein remains unknown and should be further investigated.

Nevertheless, in combination with the PiS, the S14F variant might add a negative effect. The PiS variant has been found at high frequency in the Iberian Peninsula [37,38]. The frequency of the PiSDonosti allele and its consequences are still unknown. The S14F variant was found in databases (ExAc), although its frequency in Spain has not been determined yet. It is possible that a portion of the alleles classified as PiS were in fact PiS-like alleles contributing to the phenotypic variability of the disease.

It is worth mentioning that not all AATD-causing mutations form polymers [10]. Two of the mutants described in our study, E151K and K328E, did not polymerize inside the cells and are secreted. Nevertheless, these AAT variants involve amino acids exposed at the surface of the protein that might be important for the formation of protein-protein or protein-lipid complexes. Since elastase is the main target enzyme of AAT [39], anti-elastase activity was determined for these variants. While the $\mathrm{E} 151 \mathrm{~K}$ was found to inhibit elastase in a comparable manner to the wt AAT, the K328E showed significantly lower anti-elastase activity. In addition, pulse-chase experiments revealed that K328E variant is intracellularly stabilized although its accumulation seemed to be independent of the polymerization of misfolded AAT. An interaction with other proteins or lipids inside the cell or increased synthesis could be few putative explanations for this behavior. The K328E (PiValencia) variant was found in emphysema MS patient having serum AAT levels of $87 \mathrm{mg} / \mathrm{dL}$ suggesting both serum AAT deficiency and dysfunction.

Amino acid substitutions in AAT may have different consequences. Table 2 summarizes the in silico predicted functional effects of the genetic changes described in this study. Although in some cases these predictions could be helpful in determining the pathogenic effect of the variant, in some cases they provided contradictory results. Thus, functional studies are essential in order to unravel the molecular consequences of the newly identified missense variants.

Still, the clinical impact of these new mutations is uncertain. The risk of liver disease in AATD is related to abnormal AAT polymerization $[40,41]$ while the risk for lung disease is dependent on the severity of the secreted AAT deficiency, with a protective threshold established in $11 \mathrm{microM} / \mathrm{L}$ or $57 \mathrm{mg} / \mathrm{dl}[42,43]$. In our cohort, only one patient (case 4) presented with severe AAT deficiency 
$(35 \mathrm{mg} / \mathrm{dl})$, and his genotype was a combination of PiSevilla and Z. Accordingly, the patient with a moderate smoking history had been diagnosed with severe COPD. One of the patients (case 2) had a moderate AATD, although his AAT levels were not lower than expected for a SZ genotype $(65 \mathrm{mg} / \mathrm{dl})$. In this case, the lung disease (IPF) has not been related to the AATD. The potential role of AATD in the pathophysiology and prognosis of IPF, although interesting, exceeds the aim of this study [44].

PiValencia and PiTijarafe have been incidental findings in healthy individuals (case 8) and patients (case 3) with unrelated disease to AATD. Since these deleterious variants occurred in heterozygosity with the presence of one normal $\mathrm{M}$ allele, one may not expect a significant clinical impact. The relationship between the development of lung disease and the PiSDonosti (case 1) and PiPuerto Real (case 7) variants is also less probable, even though recent studies indicated heterozygous MZ have a poorer prognosis than MM individuals [45]. Regarding case 5, which has PiM/PiCadiz genotype and asthma, we were not able to find a pathologic property of the new variant in vitro. The AATD has been suggested but not proven to be related with development of asthma [46]. Therefore, we consider PiCadiz mutation more likely to be an incidental finding rather than a deleterious factor for this patient.

In conclusion, we have identified seven novel variants of SERPINA1 gene that can help to explain the discrepancies found between serum AAT levels and genotype in eight Spanish patients with AATD. Our results suggest that rare variants might be more frequent than expected, and therefore, in discordant cases, standardized PCR screening of the S and Z alleles' needs complementation with sequencing of the gene. Functional analysis of variants with unknown significance should also be performed in doubtful cases to get a definitive diagnosis.

\section{ACKNOWLEDGMENTS}

We thank collaborators from the REDAAT (Spanish Registry of Alpha-1 Antitrypsin deficiency patients) and all members of the Genetic Diagnostic Unit and the Human Genetics Area of the ISCIII for their support. This work was funded by grant AESI PI14CIII/00070. 


\section{TABLES}

Table 1. Clinical data from eight cases with discordant initial genotype and AAT serum levels.

\begin{tabular}{|c|c|c|c|c|c|c|c|c|c|c|}
\hline Case & Gender & $\begin{array}{l}\text { Age } \\
\text { (years) }\end{array}$ & $\begin{array}{l}\text { Indication for } \\
\text { AAT screening }\end{array}$ & $\begin{array}{l}\text { Smoking } \\
\text { status }\end{array}$ & $\begin{array}{l}\text { Pack } \\
\text { /year }\end{array}$ & Diagnoses & $\begin{array}{l}\text { AAT serum } \\
\text { (mg/dl) }\end{array}$ & $\begin{array}{l}\text { Allele specific } \\
\text { genotype (S/Z) }\end{array}$ & $\begin{array}{l}\text { New AAT } \\
\text { variant }\end{array}$ & Final genotype \\
\hline 1 & Female & 59 & Lung disease & Former & 30 & Mild COPD & 76 & SS & PiSDonosti & PiS/PiSDonosti \\
\hline 2 & Male & 40 & Lung disease & Never & 0 & IPF & 67 & $S Z$ & PiSDonosti & PiZ/PiSDonosti \\
\hline 3 & Male & 39 & Incidental finding & Never & 0 & $\begin{array}{l}\text { Chronic } \\
\text { diarrhea }\end{array}$ & 75 & NoS No Z & PiTijarafe & PiM/ PiTijarafe \\
\hline 4 & Male & 64 & Lung disease & Former & 22 & Severe COPD & 35 & Heterozygous Z & PiSevilla & Piz/PiSevilla \\
\hline 5 & Male & 67 & Lung disease & Never & 0 & Asthma & 81 & No S no Z & PiCadiz & PiM/ PiCadiz \\
\hline 6 & Male & 64 & Lung disease & Current & 80 & Severe COPD & 85 & Heterozygous S & PiTarragona & PiS/PiTarragona \\
\hline 7 & Male & 68 & Lung disease & Former & 50 & Mild COPD & 75 & No S no Z & PiPuerto Real & PiM/PiPuerto Real \\
\hline 8 & Female & 38 & Family screening & Never & 0 & Healthy & 87 & Heterzygous S & PiValencia & PiS/ PiValencia \\
\hline
\end{tabular}

Table 2. Description of the seven novel alleles of SERPINA1 identified in Spanish cases of AATD.

\begin{tabular}{|c|c|c|c|c|c|c|c|c|}
\hline Case & Allele name & Sequence & Codon & Mature protein & dhSNE & $\mathbf{M A * *}$ & Functional Prediction & Physiopathological \\
\hline Cuse & Allete inite & Change & Change & change* & CDSIVI & MAT & POLYPHEN & consequences \\
\hline
\end{tabular}




\begin{tabular}{|c|c|c|c|c|c|c|c|c|c|}
\hline $1 \& 2$ & PiSDonosti & TCC>TTC & Ser38Phe & $\begin{array}{c}S+\text { Serl } 4 \text { Phe } \\
(S+S 14 F)\end{array}$ & rs745463238 & $<1 / 10,000$ & Tolerated & $\begin{array}{l}\text { Possibly } \\
\text { Damaging }\end{array}$ & $\begin{array}{l}\text { - Intracellular polymerization } \\
\text { - Intracellular degradation } \\
\text { - AAT reduced secretion }\end{array}$ \\
\hline 3 & PiTijarafe & ATC $>A A C$ & Ile74Asn & $\begin{array}{c}\text { Ile50Asn } \\
\text { (I50N) }\end{array}$ & - & - & Deletereous & $\begin{array}{l}\text { Probably } \\
\text { Damaging }\end{array}$ & $\begin{array}{l}\text { - Intracellular polymerization } \\
\text { - Intracellular stabilization } \\
\text { - AAT reduced secretion }\end{array}$ \\
\hline 4 & PiSevilla & GCT>GAT & Ala82Asp & $\begin{array}{c}\text { Ala58Asp } \\
\text { (A58D) }\end{array}$ & - & - & Tolerated & $\begin{array}{l}\text { Possibly } \\
\text { Damaging }\end{array}$ & $\begin{array}{l}\text { - Intracellular polymerization } \\
\text { - Intracellular stabilization } \\
\text { - AAT reduced secretion }\end{array}$ \\
\hline 5 & PiCadiz & GAA>AAA & Glu175Lys & $\begin{array}{l}\text { Glu151Lys } \\
\text { (E151K) }\end{array}$ & rs 149770048 & $<1 / 10,000$ & Tolerated & Benign & None \\
\hline 6 & PiTarragona & TTT>TGT & Phe251Cys & $\begin{array}{c}\text { Phe227Cys } \\
\text { (F227C) }\end{array}$ & rs759837735 & Singleton & Deletereous & $\begin{array}{l}\text { Possibly } \\
\text { Damaging }\end{array}$ & $\begin{array}{l}\text { - Intracellular polymerization } \\
\text { - Intracellular degradation } \\
\text { - AAT reduced secretion }\end{array}$ \\
\hline 7 & PiPuerto Real & $A C C>G C C$ & Thr273Ala & $\begin{array}{c}\text { Thr249Ala } \\
\text { (T249A) }\end{array}$ & - & - & Deletereous & Benign & $\begin{array}{l}\text { - Intracellular polymerization } \\
\text { - Intracellular stabilization } \\
\text { - Removal of N-glycosylation } \\
\text { chain at Asn247 }\end{array}$ \\
\hline 8 & PiValencia & $A A G>G A G$ & Lys352Glu & $\begin{array}{l}\text { Lys328Glu } \\
\text { (K328E) }\end{array}$ & - & - & Deletereous & $\begin{array}{l}\text { Probably } \\
\text { Damaging }\end{array}$ & $\begin{array}{l}\text { - Reduced antielastase } \\
\text { activity } \\
\text { - Intracellular stabilization }\end{array}$ \\
\hline
\end{tabular}

*Amino acid changes corresponding to each variant were named according to the mature AAT protein amino acid sequence, without the signal peptide of 24 amino acids.

**MAF: Minor allele frequency as by ExAc. 


\section{FIGURE LEGENDS}

Figure 1. Analysis of AAT by isoelectric focusing electrophoresis (IEF) in plasma samples from subjects with different genotypes. Variant F227C was found in case 6 with the PiS/PiTarragona genotype. Plasma form this patient displays a different AAT protein phenotype, comparing with the pattern from MM, MS, MZ or SZ. Plasma from case 5 with the PiM/PiCadiz (M/E151K) genotype demonstrated additional bands not present in the MM control. However, the S14F variant found in the SZ patient (case 2, PiZ/PiSDonosti genotype) showed a clear SZ protein phenotype. Numbers at the right represent relative position of the IEF bands.

Figure 2. AAT protein expression and secretion in HEK293T cells transfected with the new identified variants. A $10 \%$ acrylamide SDS PAGE was performed on lysates and conditioned media of cells expressing wildtype (wt) SERPINA1, and variants PiS, S14F, PiS+S14F, F227C, K328E, PiZ, A58D, E151K, I50N and T249A. Blots were incubated with anti-AAT B9 (Santa Cruz Biotechnology), and anti- $\beta$-actin was used as a loading control.

* indicates the smaller size of AAT in the T249A mutant.

Figure 3. AAT polymers retained within HEK293T cells detected by PAS staining. AAT aggregates were detected by hematoxiling/eosin and PAS staining of cells expressing wildtype (wt) SERPINA1, and variants PiS, S14F, PiS+S14F, F227C, K328E, PiZ, A58D, E151K, I50N and T249A. Accumulation of AAT is seen as bright magenta globules in the cytoplasm.

Figure 4. AAT polymers retained within HEK293T cells detected by western blot. A) Detection of AAT polymers in insoluble fractions of cells expressing the different SERPINA1 variants. Extracts were run on $8 \%$ acrylamide non-denaturing PAGE and blots were incubated with anti-AAT B9 for the detection of total AAT. B) Polymer detection with $2 \mathrm{C} 1$ antibody (upper panel) or anti-total AAT (lower panel) in sonicated cells expressing the new AAT mutants and controls.

Figure 5. Elastase inhibitory activity of AAT variants secreted to the cell media. A) The increase in A405 was measured after incubation of elastase with its substrate and media from cells expressing the S14F, E151K, K328E or T249A variants. Cells transfected with SERPINA1 wt or an empty vector were used as controls. B) Normalization to the empty vector was performed to calculate the percentage of elastase activity for each mutant. Percentages are averages of three independent experiments $\pm \mathrm{SD}$.

Figure 6. Intracellular stabilization of AAT variants. A) Pulse-chase experiments on HEK293T cells expressing AAT variants shows intracellular retention of Z, I50N, A58D, T249A and K328E, but not of WT, E151K, S+S14F and F227C. B) Densitometric analysis of 
the autoradiograms shown in panel A using ImageJ. The amounts of AAT are expressed as percentage of the amount of AAT at time 0 .

Figure 7. Localization of the new AAT variants on protein tertiary structure. A) Amino acid residues corresponding to each variant are highlighted in green (new variants) or red (PiZ and PiS). B) Two variants, E151K and K328E, involve amino acids exposed at the surface of the protein. 


\section{REFERENCES}

1. Fregonese L, Stolk J (2008) Hereditary alpha-1-antitrypsin deficiency and its clinical consequences. Orphanet J Rare Dis 3: 16.

2. Blanco I, Lipsker D, Lara B, Janciauskiene S (2016) Neutrophilic panniculitis associated with alpha-1-antitrypsin deficiency: an update. Br J Dermatol 174: 753-762.

3. Miravitlles M, Herr C, Ferrarotti I, Jardi R, Rodriguez-Frias F, Luisetti M, Bals R (2010) Laboratory testing of individuals with severe alpha1-antitrypsin deficiency in three European centres. Eur Respir J 35: 960-968.

4. Snyder MR, Katzmann JA, Butz ML, Wiley C, Yang P, Dawson DB, Halling KC, Highsmith WE, Thibodeau SN (2006) Diagnosis of alpha-1-antitrypsin deficiency: An algorithm of quantification, genotyping, and phenotyping. Clin Chem 52: 22362242.

5. American Thoracic Society/European Respiratory Society statement: standards for the diagnosis and management of individuals with alpha-1 antitrypsin deficiency. (2003). Am J Respir Crit Care Med 168: 818-900.

6. Kueppers $F$ (1976) Determination of alpha1-antitrypsin phenotypes by isoelectric focusing in polyacrylamide gels. J Lab Clin Med 88: 151-155.

7. Belmonte I, Barrecheguren M, Lopez-Martinez RM, Esquinas C, Rodriguez E, Miravitlles $M$, Rodriguez-Frias F (2016) Application of a diagnostic algorithm for the rare deficient variant Mmalton of alpha-1-antitrypsin deficiency: a new approach. Int J Chron Obstruct Pulmon Dis 11: 2535-2541.

8. von AN, Oellerich M, Schutz E (2000) Use of two reporter dyes without interference in a single-tube rapid-cycle PCR: alpha(1)-antitrypsin genotyping by multiplex realtime fluorescence PCR with the LightCycler. Clin Chem 46: 156-161.

9. Lara B, Martinez MT, Blanco I, Hernandez-Moro C, Velasco EA, Ferrarotti I, RodriguezFrias F, Perez L, Vazquez I, Alonso J, Posada M, Martinez-Delgado B (2014) Severe alpha-1 antitrypsin deficiency in composite heterozygotes inheriting a new splicing mutation QOMadrid. Respir Res 15: 125.

10. Salahuddin P (2010) Genetic variants of alpha1-antitrypsin. Curr Protein Pept Sci 11: 101117.

11. Gooptu B, Dickens JA, Lomas DA (2014) The molecular and cellular pathology of alpha(1)antitrypsin deficiency. Trends Mol Med 20: 116-127.

12. Lomas DA, Elliott PR, Sidhar SK, Foreman RC, Finch JT, Cox DW, Whisstock JC, Carrell RW (1995) alpha 1-Antitrypsin Mmalton (Phe52-deleted) forms loop-sheet polymers in vivo. Evidence for the $C$ sheet mechanism of polymerization. J Biol Chem 270: 16864-16870.

13. Lomas DA, Evans DL, Finch JT, Carrell RW (1992) The mechanism of $Z$ alpha 1-antitrypsin accumulation in the liver. Nature 357: 605-607. 
14. Silva D, Oliveira MJ, Guimaraes M, Lima R, Gomes S, Seixas S (2016) Alpha-1-antitrypsin (SERPINA1) mutation spectrum: Three novel variants and haplotype characterization of rare deficiency alleles identified in Portugal. Respir Med 116: 8-18.

15. Fra AM, Gooptu B, Ferrarotti I, Miranda E, Scabini R, Ronzoni R, Benini F, Corda L, Medicina D, Luisetti M, Schiaffonati L (2012) Three new alpha1-antitrypsin deficiency variants help to define a C-terminal region regulating conformational change and polymerization. PLoS One 7: e38405.

16. Joly P, Lacan P, Chapuis-Cellier C, Garcia C, Bererd M, Francina A (2014) Molecular characterization of 7 new alpha-1 anti-trypsin (A1AT) variants including two with an associated deficient phenotype. Clin Chim Acta 427: 21-22.

17. Vidal R, Blanco I, Casas F, Jardi R, Miravitlles M (2006) [Guidelines for the diagnosis and management of alpha-1 antitrypsin deficiency]. Arch Bronconeumol 42: 645-659.

18. Lara B, Martinez-Delgado B, Torres ML, Marin-Arguedas S, Bustamante A, Miravitlles M (2013) Alpha-1-antitrypsin deficiency associated with the Mattawa variant. Arch Bronconeumol 49: 548-550.

19. Zorzetto M, Russi E, Senn O, Imboden M, Ferrarotti I, Tinelli C, Campo I, Ottaviani S, Scabini R, von EA, Berger W, Brandli O, Rochat T, Luisetti M, Probst-Hensch N (2008) SERPINA1 gene variants in individuals from the general population with reduced alpha1-antitrypsin concentrations. Clin Chem 54: 1331-1338.

20. Ferrarotti I, Scabini R, Campo I, Ottaviani S, Zorzetto M, Gorrini M, Luisetti M (2007) Laboratory diagnosis of alpha1-antitrypsin deficiency. Transl Res 150: 267-274.

21. Patschull AO, Segu L, Nyon MP, Lomas DA, Nobeli I, Barrett TE, Gooptu B (2011) Therapeutic target-site variability in alpha1-antitrypsin characterized at high resolution. Acta Crystallogr Sect F Struct Biol Cryst Commun 67: 1492-1497.

22. Humphrey W, Dalke A, Schulten K (1996) VMD: visual molecular dynamics. J Mol Graph 14: 33-38.

23. Cox DW, Johnson AM, Fagerhol MK (1980) Report of Nomenclature Meeting for alpha 1antitrypsin, INSERM, Rouen/Bois-Guillaume-1978. Hum Genet 53: 429-433.

24. Tagliabracci VS, Wiley SE, Guo X, Kinch LN, Durrant E, Wen J, Xiao J, Cui J, Nguyen KB, Engel JL, Coon JJ, Grishin N, Pinna LA, Pagliarini DJ, Dixon JE (2015) A Single Kinase Generates the Majority of the Secreted Phosphoproteome. Cell 161: 1619-1632.

25. Lomas DA, Mahadeva R (2002) Alpha1-antitrypsin polymerization and the serpinopathies: pathobiology and prospects for therapy. J Clin Invest 110: 15851590.

26. Cox DW, Billingsley GD, Callahan JW (1986) Aggregation of plasma Z type alpha 1antitrypsin suggests basic defect for the deficiency. FEBS Lett 205: 255-260. 
27. Lomas DA, Finch JT, Seyama K, Nukiwa T, Carrell RW (1993) Alpha 1-antitrypsin Siiyama (Ser53-->Phe). Further evidence for intracellular loop-sheet polymerization. J Biol Chem 268: 15333-15335.

28. Mahadeva R, Chang WS, Dafforn TR, Oakley DJ, Foreman RC, Calvin J, Wight DG, Lomas DA (1999) Heteropolymerization of S, I, and Z alpha1-antitrypsin and liver cirrhosis. J Clin Invest 103: 999-1006.

29. Martin SL, Downey D, Bilton D, Keogan MT, Edgar J, Elborn JS (2006) Safety and efficacy of recombinant alpha(1)-antitrypsin therapy in cystic fibrosis. Pediatr Pulmonol 41: 177-183.

30. McCarthy C, Saldova R, O'Brien ME, Bergin DA, Carroll TP, Keenan J, Meleady P, Henry M, Clynes M, Rudd PM, Reeves EP, McElvaney NG (2014) Increased outer arm and core fucose residues on the $\mathrm{N}$-glycans of mutated alpha- 1 antitrypsin protein from alpha-1 antitrypsin deficient individuals. J Proteome Res 13: 596-605.

31. McCarthy C, Saldova R, Wormald MR, Rudd PM, McElvaney NG, Reeves EP (2014) The role and importance of glycosylation of acute phase proteins with focus on alpha-1 antitrypsin in acute and chronic inflammatory conditions. J Proteome Res 13: 3131-3143.

32. McElvaney NG, Hubbard RC, Birrer P, Chernick MS, Caplan DB, Frank MM, Crystal RG (1991) Aerosol alpha 1-antitrypsin treatment for cystic fibrosis. Lancet 337: 392394.

33. Anelli T, Sitia R (2008) Protein quality control in the early secretory pathway. EMBO J 27: 315-327.

34. Yamasaki M, Li W, Johnson DJ, Huntington JA (2008) Crystal structure of a stable dimer reveals the molecular basis of serpin polymerization. Nature 455: 1255-1258.

35. Curiel DT, Chytil A, Courtney M, Crystal RG (1989) Serum alpha 1-antitrypsin deficiency associated with the common S-type (Glu264----Val) mutation results from intracellular degradation of alpha 1-antitrypsin prior to secretion. J Biol Chem 264: 10477-10486.

36. Bian Y, Song C, Cheng K, Dong M, Wang F, Huang J, Sun D, Wang L, Ye M, Zou H (2014) An enzyme assisted RP-RPLC approach for in-depth analysis of human liver phosphoproteome. J Proteomics 96: 253-262.

37. Blanco I, Bustillo EF, Rodriguez MC (2001) Distribution of alpha1-antitrypsin PI S and PI Z frequencies in countries outside Europe: a meta-analysis. Clin Genet 60: 431441.

38. Blanco I, de Serres FJ, Fernandez-Bustillo E, Lara B, Miravitlles M (2006) Estimated numbers and prevalence of $\mathrm{PI} * \mathrm{~S}$ and $\mathrm{PI} * \mathrm{Z}$ alleles of alpha1-antitrypsin deficiency in European countries. Eur Respir J 27: 77-84.

39. Gadek JE, Fells GA, Zimmerman RL, Rennard SI, Crystal RG (1981) Antielastases of the human alveolar structures. Implications for the protease-antiprotease theory of emphysema. J Clin Invest 68: 889-898. 
40. Fairbanks KD, Tavill AS (2008) Liver disease in alpha 1-antitrypsin deficiency: a review. Am J Gastroenterol 103: 2136-2141.

41. Pittschieler K (2002) Liver involvement in alpha1-antitrypsin-deficient phenotypes PiSZ and PiMZ. Acta Paediatr 91: 239-240.

42. Turino GM, Barker AF, Brantly ML, Cohen AB, Connelly RP, Crystal RG, Eden E, Schluchter MD, Stoller JK (1996) Clinical features of individuals with PI*SZ phenotype of alpha 1-antitrypsin deficiency. alpha 1-Antitrypsin Deficiency Registry Study Group. Am J Respir Crit Care Med 154: 1718-1725.

43. Stoller JK, Lacbawan FL, Aboussouan LS (1993) Alpha-1 Antitrypsin Deficiency.

44. Stanley SE, Merck SJ, Armanios M (2016) Telomerase and the Genetics of Emphysema Susceptibility. Implications for Pathogenesis Paradigms and Patient Care. Ann Am Thorac Soc 13: S447-S451.

45. Silverman EK (2016) Risk of Lung Disease in PI MZ Heterozygotes. Current Status and Future Research Directions. Ann Am Thorac Soc 13 Suppl 4: S341-S345.

46. Casas F, Blanco I, Martinez MT, Bustamante A, Miravitlles M, Cadenas S, Hernandez JM, Lazaro L, Rodriguez E, Rodriguez-Frias F, Torres M, Lara B (2015) Indications for active case searches and intravenous alpha-1 antitrypsin treatment for patients with alpha-1 antitrypsin deficiency chronic pulmonary obstructive disease: an update. Arch Bronconeumol 51: 185-192. 


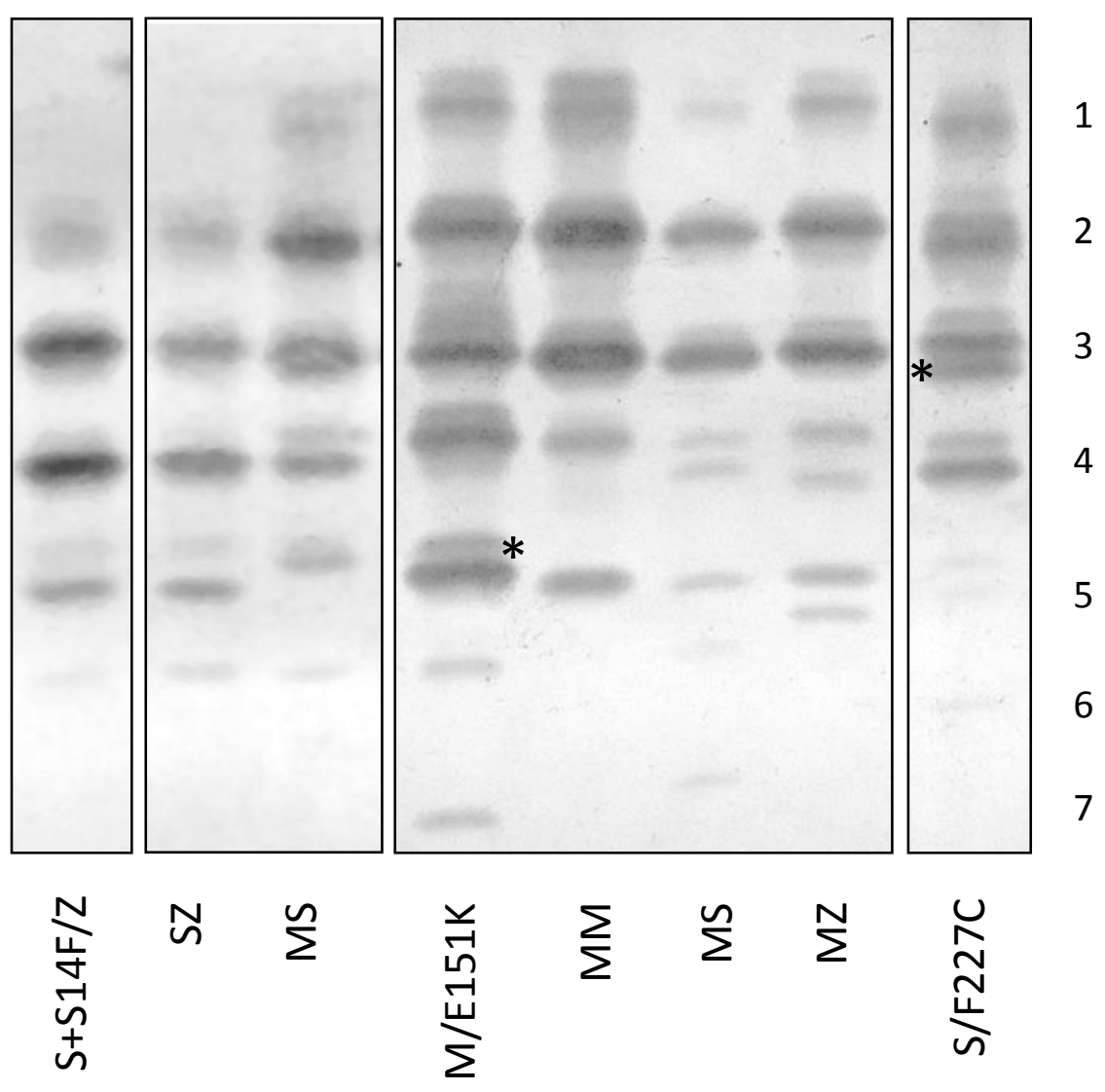

Figure 1 


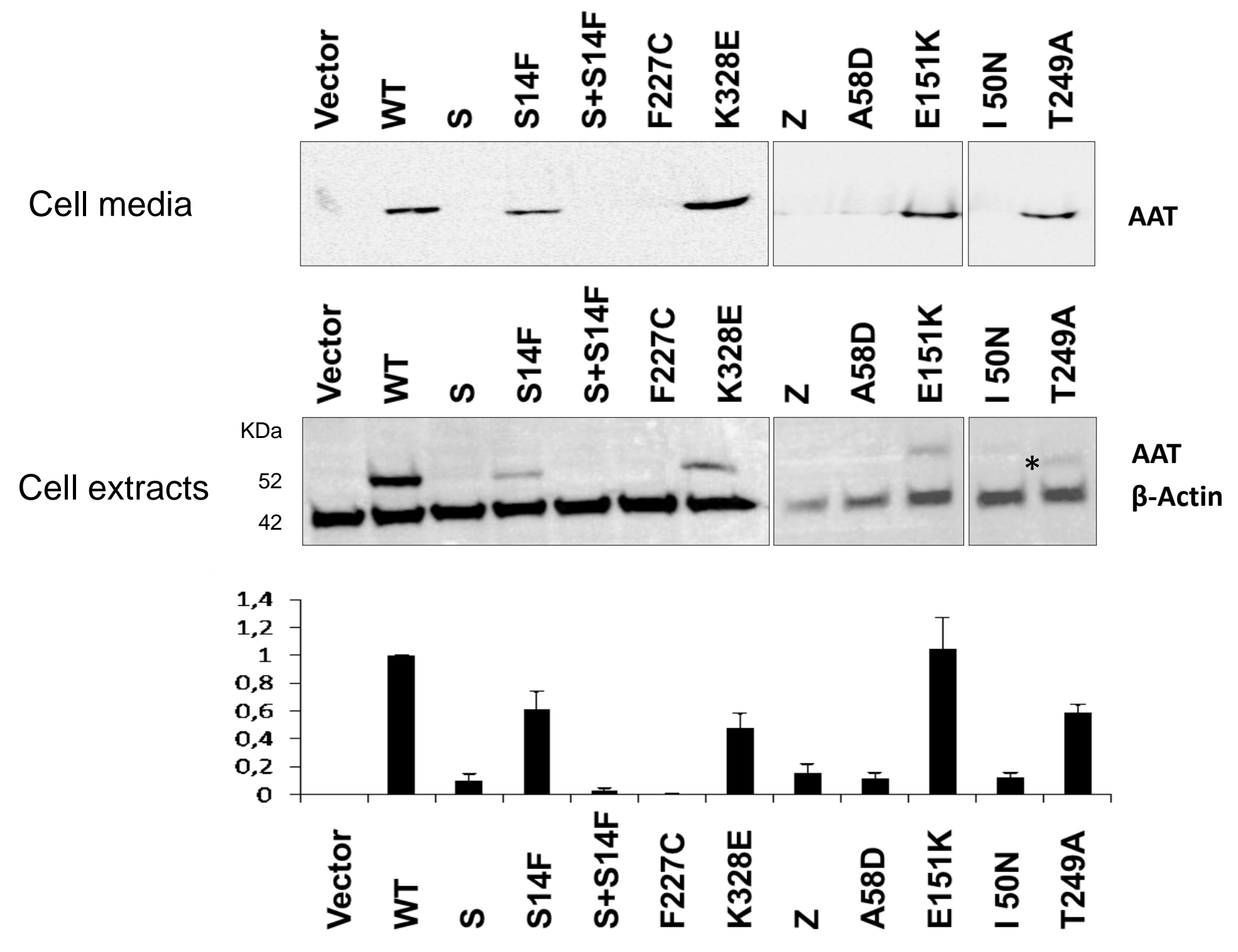

Figure 2 


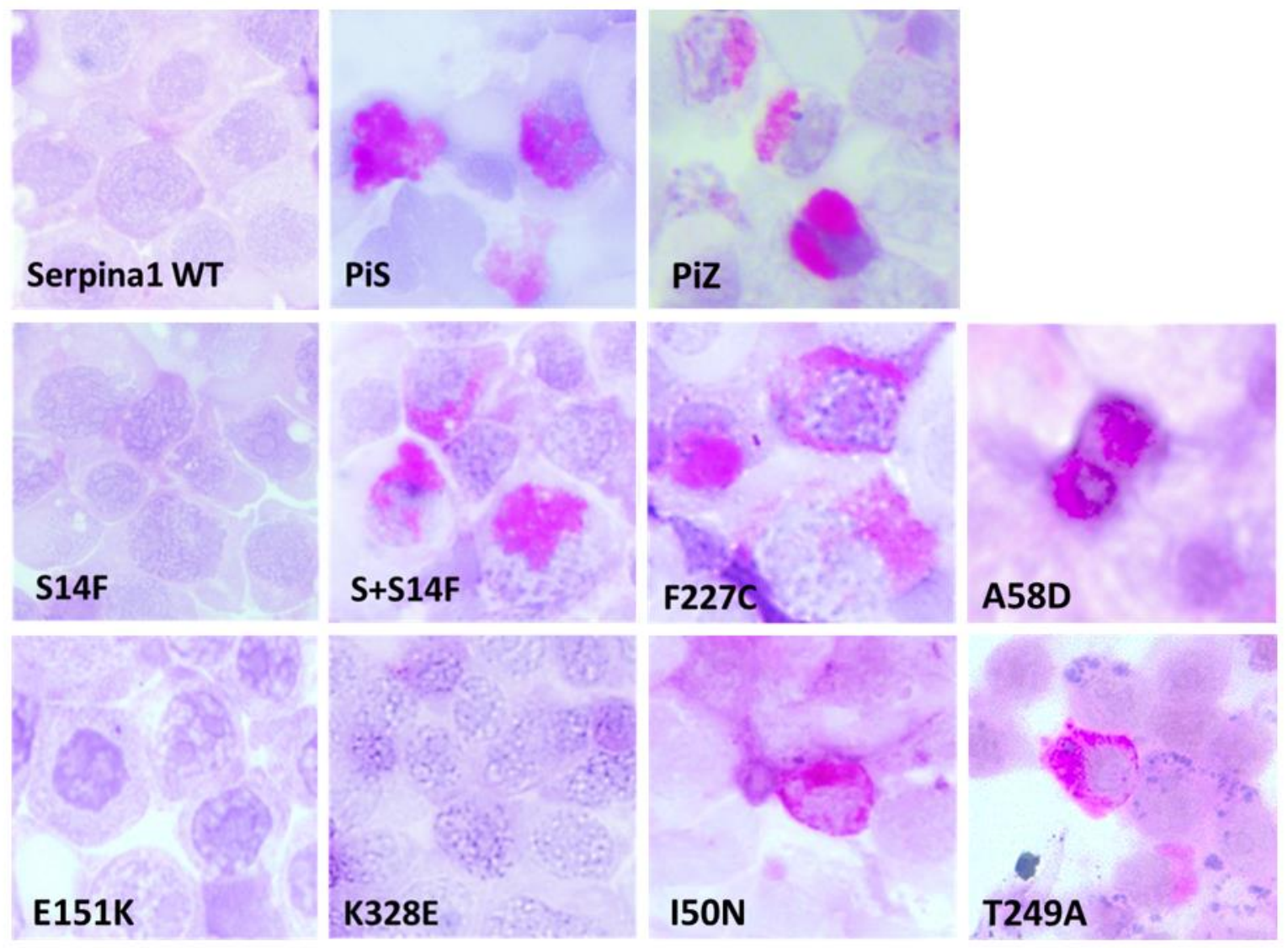

Figure 3 
a)

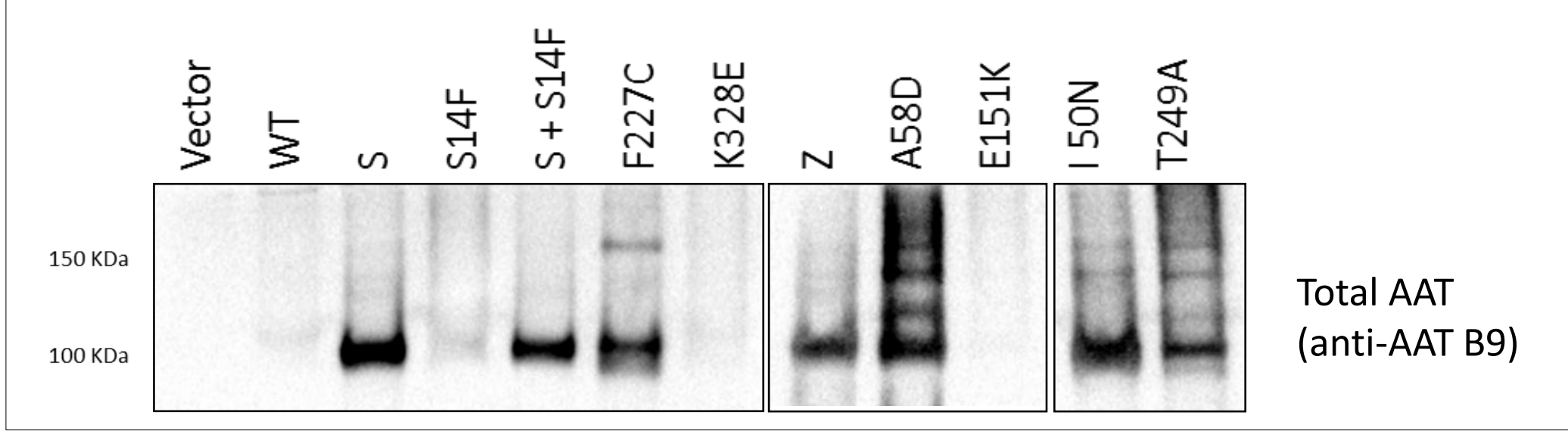

b)

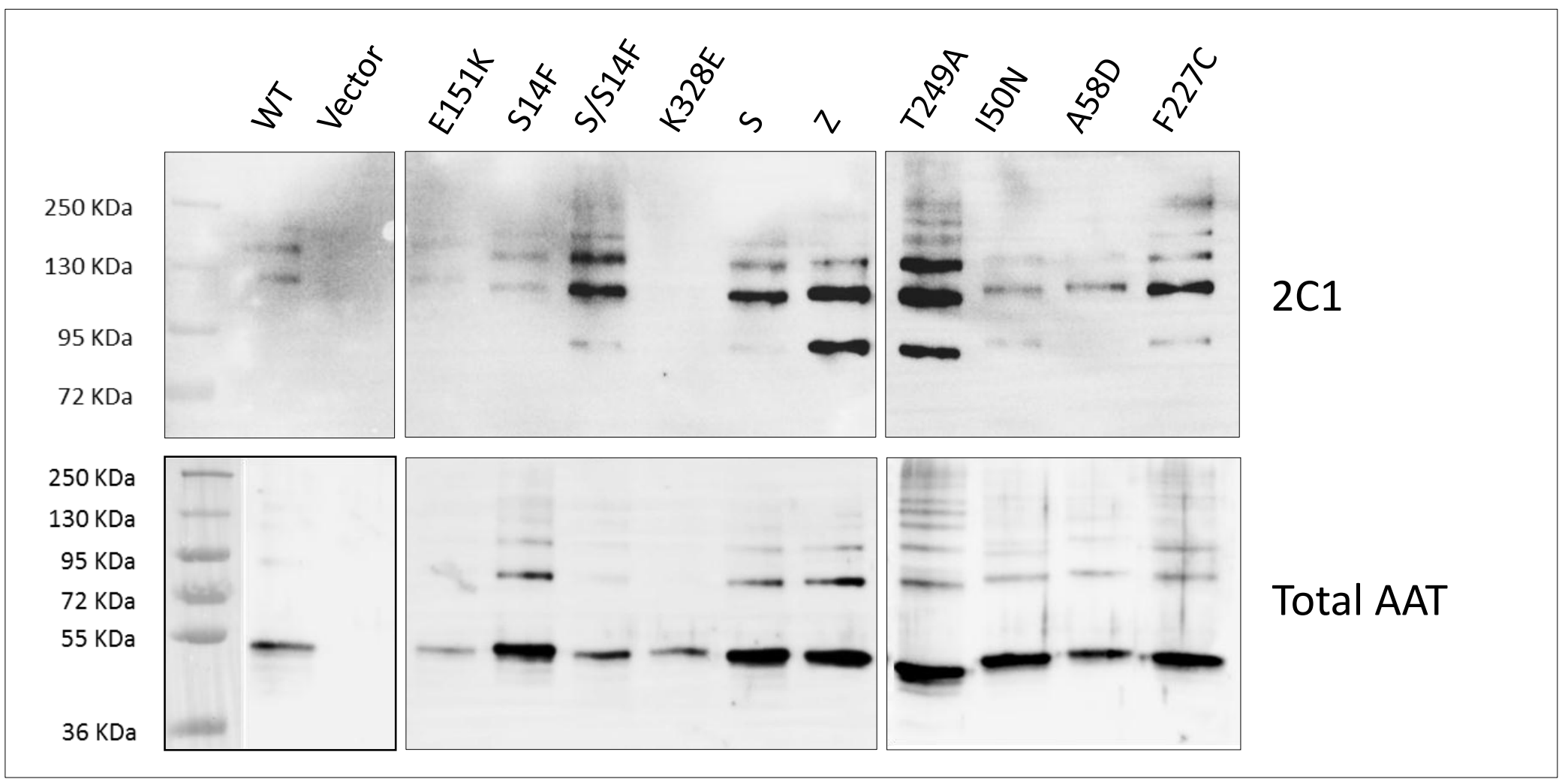

Figure 4 
a)

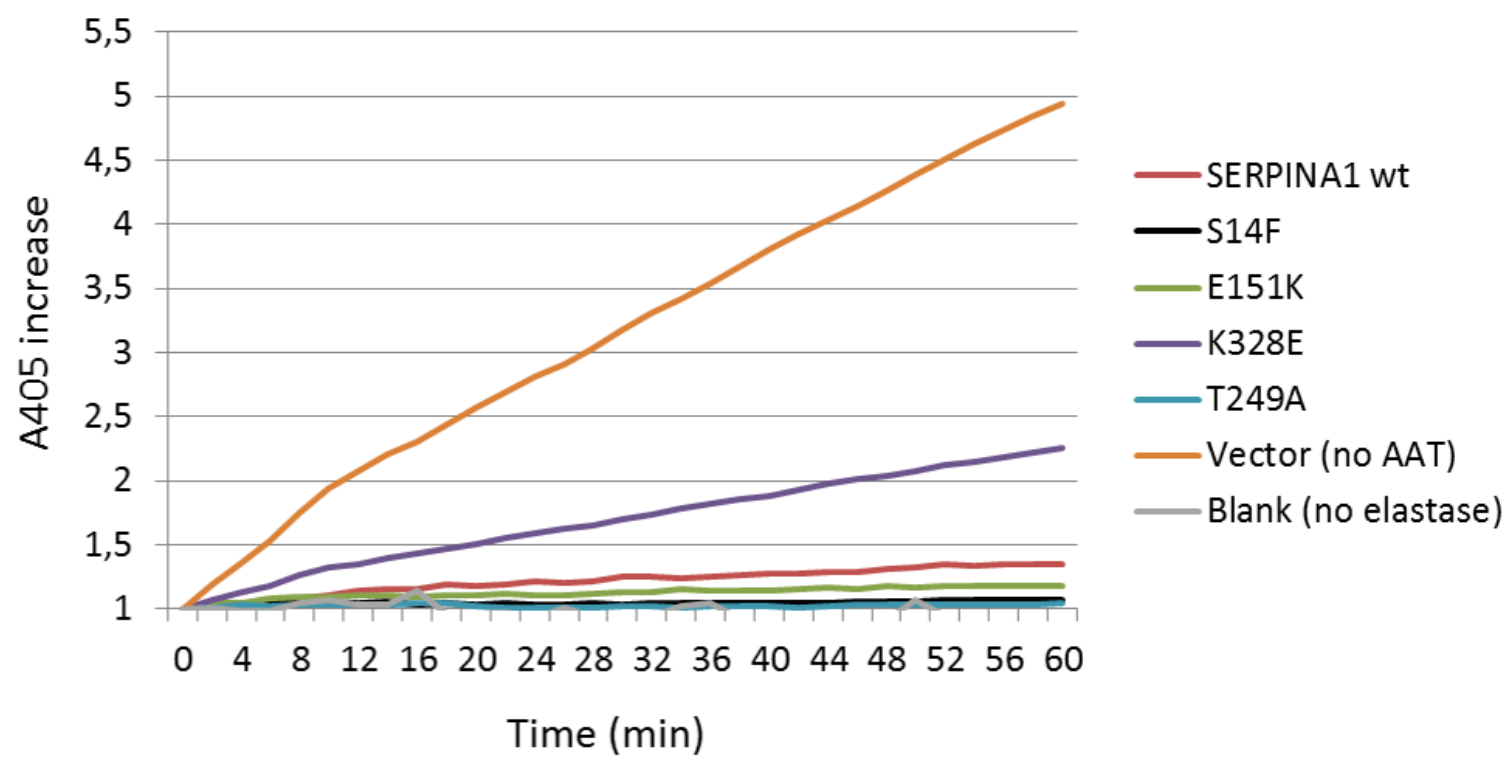

b)

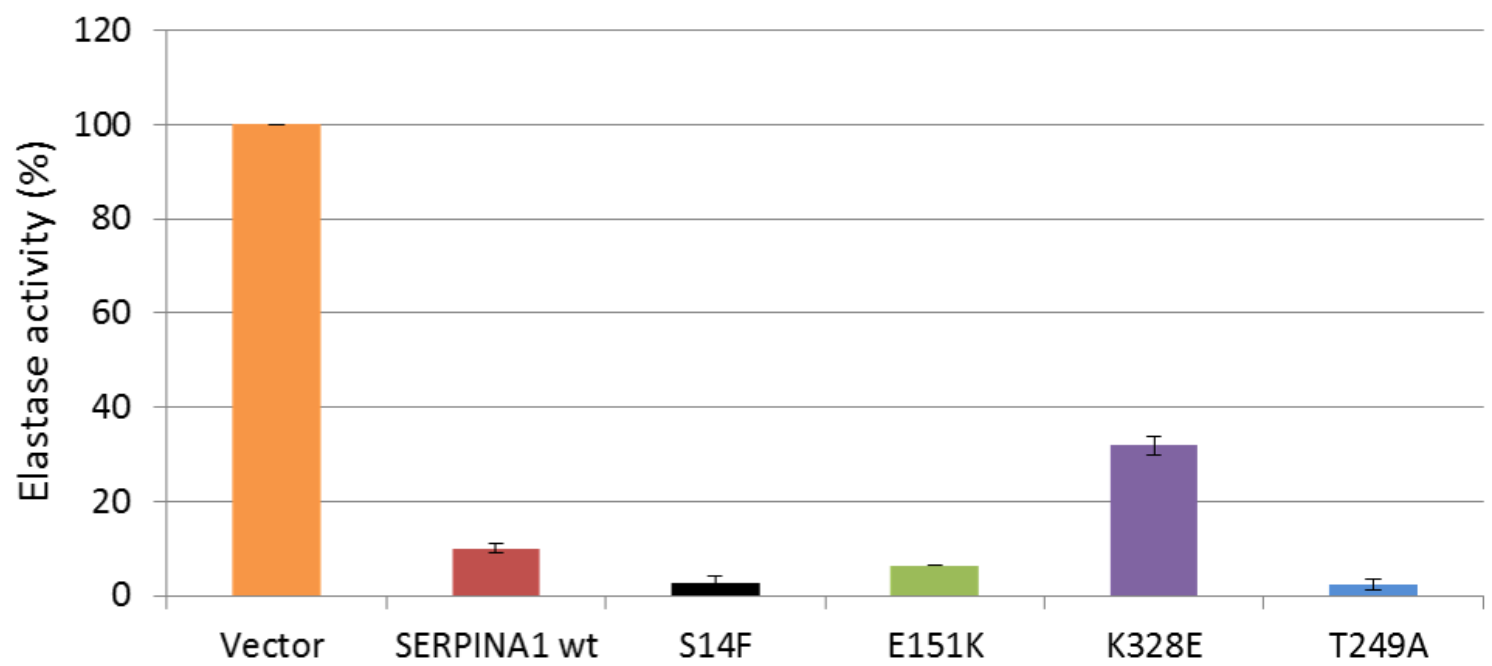

Figure 5 
a)
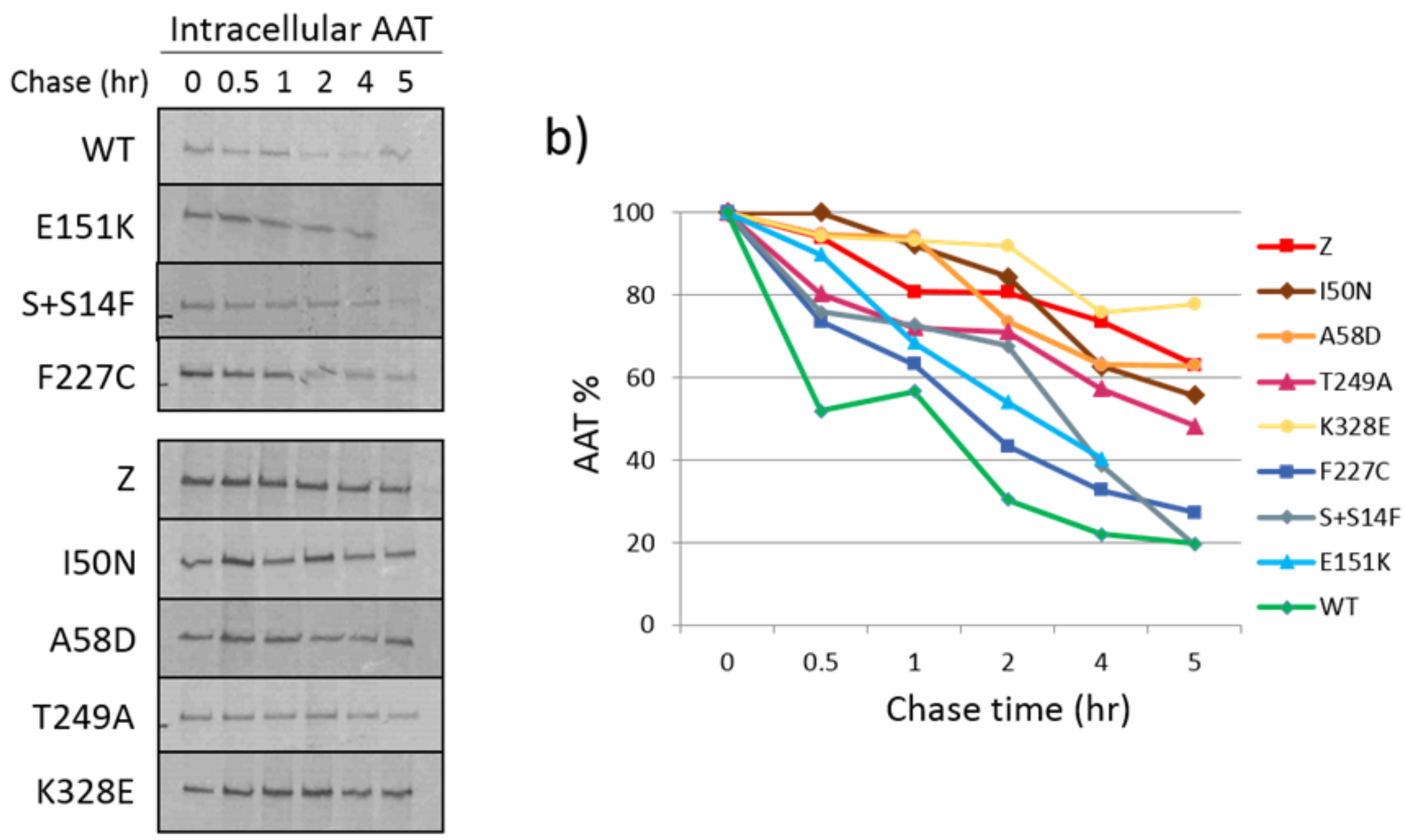

Figure 6 
a)

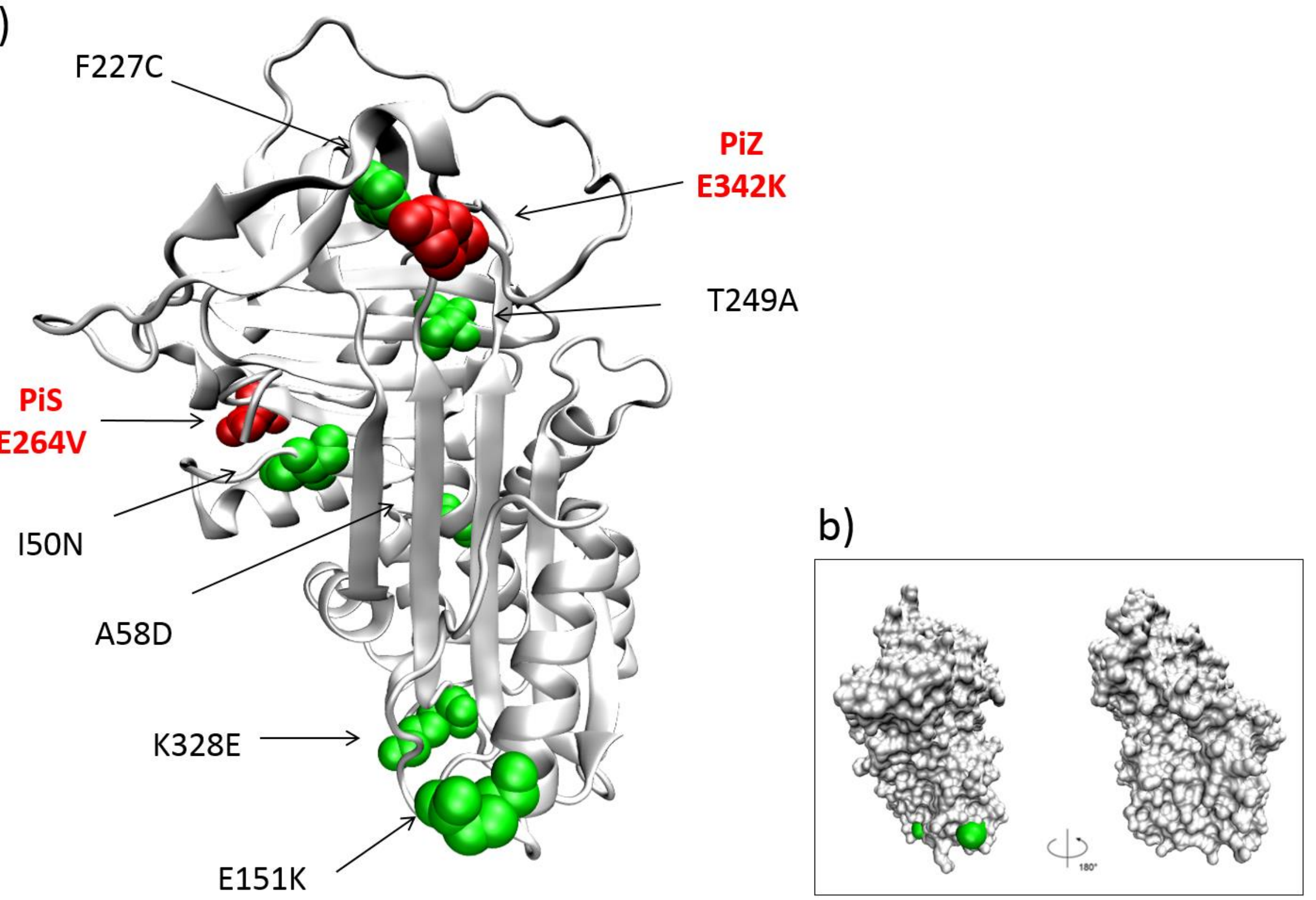

Figure 7 